\title{
Abdominal wall muscle metastases from breast cancer - A rare occurrence and treatment dilemma
}

\author{
Harjit K Perdamen $^{1 *}$, Raveena K Dhadli ${ }^{2}$, Sharifah Noor Akmal ${ }^{3}$ and Rachael Khong ${ }^{4}$ \\ ${ }^{1}$ Consultant Breast and Endocrine Surgeon, Gleneagles Kuala Lumpur, Malaysia \\ ${ }^{2} 2^{\text {nd }}$ Year Medical Student, Royal College of Surgeons in Ireland, Dublin, Ireland \\ ${ }^{3}$ Consultant Pathologist, Gleneagles Kuala Lumpur, Malaysia \\ ${ }^{4}$ Consultant Oncologist, Gleneagles Kuala Lumpur, Malaysia
}

\section{Introduction}

Breast Cancer is the most common cancer affecting women worldwide, and in Malaysia. The most common sites of metastases are bone, liver and lung [1]. Skeletal muscle involvement in various parts of the body have been reported in literature. However, the disease presentations have been varied, so long-term treatment and follow up recommendations of patients are still a debate.

We report a young woman with invasive ductal carcinoma with an enlarging metastatic nodule in the right anterior abdominal wall muscle. The immunohistochemistry of the metastatic nodule appears to differ from the primary breast tumour. The patients treatment plan and follow up is discussed.

\section{Case report}

A 36-year-old Indonesian woman presented with a left breast mass lesion, which seemed suspicious on ultrasound. She has no family history of breast cancer and was otherwise well. A mammogram ruled out multifocal disease, and a biopsy was done which confirmed a Grade 3 invasive ductal carcinoma of the breast.

A preoperative CT scan (Figure 1) was clear of metastases. A small nodule was noted on the right lower abdominal wall and was reported as a sebaceous cyst at that time.

Her preoperative blood investigations were generally fine with normal haemoglobin, white cell count and platelets. Her liver function was normal. Her Carcino-Embryonic Antigen was less than $0.5 \mathrm{ug} / \mathrm{L}$, Ca125 was $16.1 \mathrm{U} / \mathrm{mL}$ and Ca153 was $16.3 \mathrm{U} / \mathrm{mL}$, which were all within normal limits.

She underwent a left breast wide local excision and a sentinel node biopsy uneventfully in July 2016. The final pathology report was a Grade 3 Invasive Ductal Carcinoma (Slide 1), which was $1.5 \mathrm{~cm}$ with clear margins. Three sentinel nodes were clear of metastases. Estrogen receptors (Slide 2) and progesterone receptors (Slide 3) were negative. Her- 2 was positive. Ki67 was at $60 \%$, which is high.

She underwent 6 cycles of chemotherapy (FEC) and Radiotherapy to the left breast with $40 \mathrm{~Gy} / 15$ Fraction plus a $10 \mathrm{~Gy}$ boost at a different medical centre. She was followed up regularly by the oncologist there and was apparently well. Regular ultrasounds were done, which were apparently normal.

In August 2017, she returned from Indonesia complaining of an enlarging abdominal mass lesion.

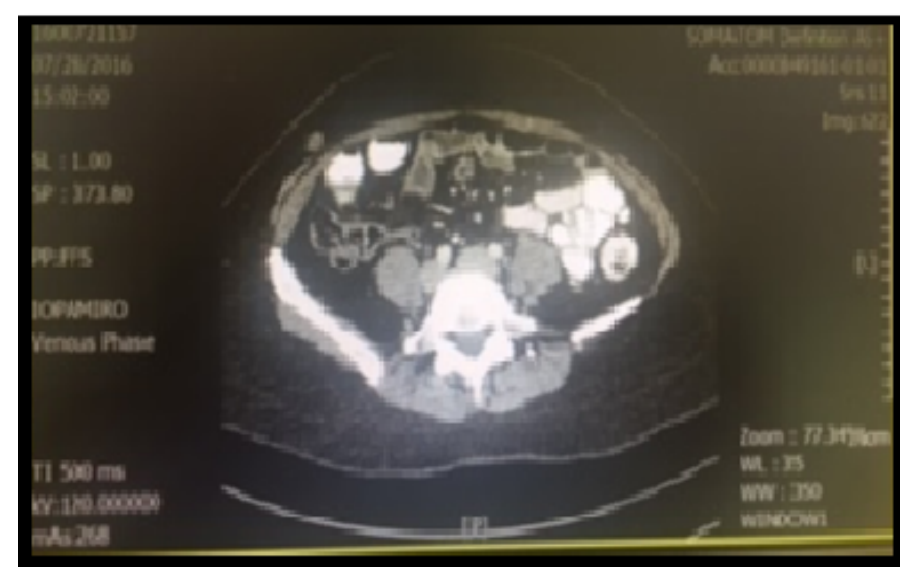

Figure 1. CT Scan image on preoperative staging (July 2016)

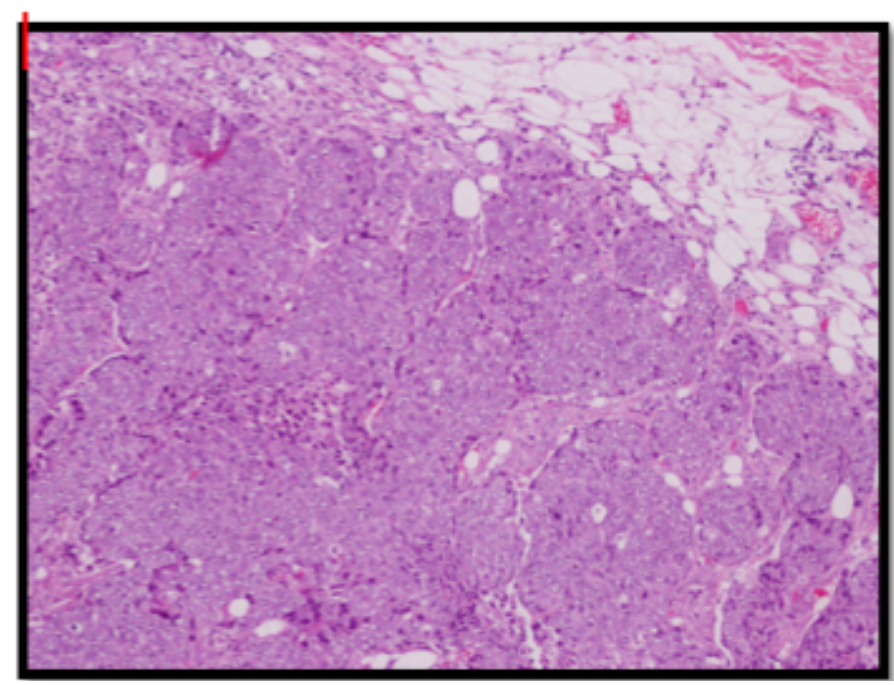

Slide 1. High Grade Invasive Ductal Carcinoma - primary breast tumour.

Correspondence to: Harjit K Perdamen, Consultant Breast and Endocrine Surgeon, Gleneagles Kuala Lumpur, Malaysia; E-mail: Harjitdr67@yahoo.com

Key words: Pathological analysis, Ductal breast cancer, Lymph node metastasis

Received: October 29, 2017; Accepted: November 30, 2017; Published: December 04, 2017 


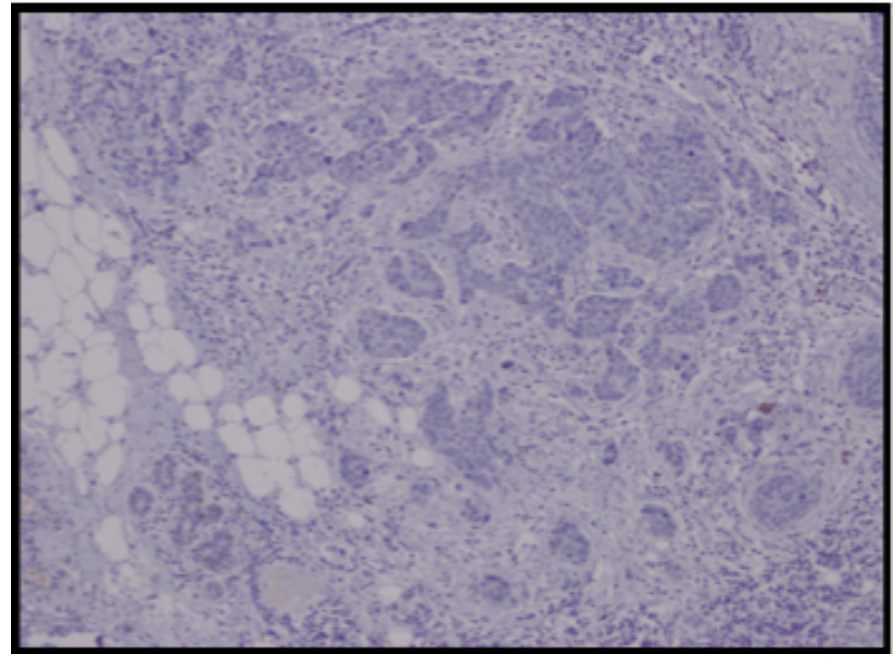

Slide 2. Estrogen receptor negative - primary breast tumour.

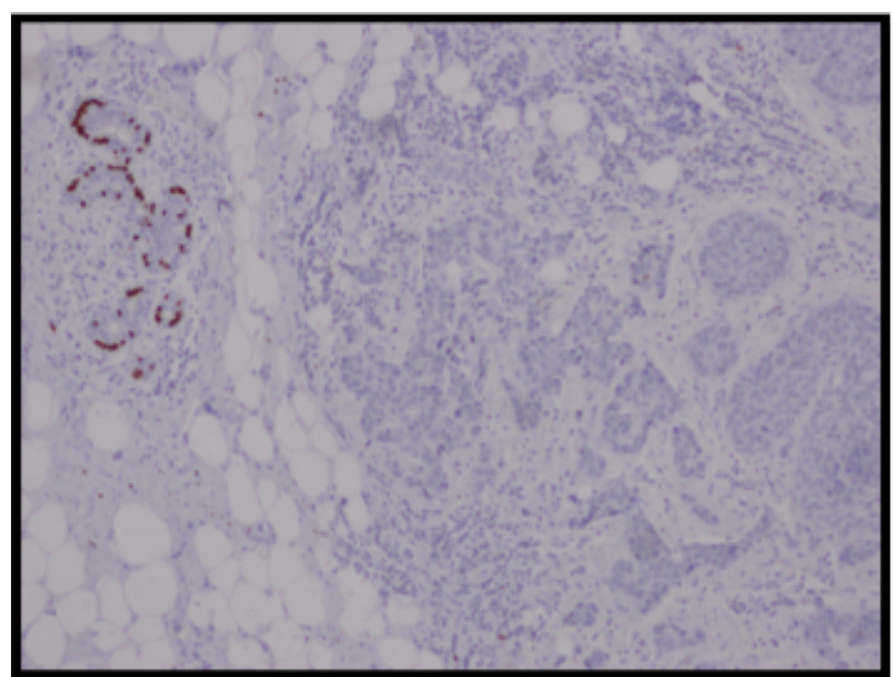

Slide 3. Progesterone receptor negative - primary breast tumour.

Clinically, a fairly well defined smooth mass lesion was palpable in the right lower abdomen. It appeared subcutaneous, measuring $17 \times 19 \mathrm{~mm}$ on bedside ultrasound. A CT scan (Figure 2) confirmed an isolated lobulated mass in the deep subcutaneous plane of the right anterolateral abdominal wall. It appeared to be infiltrating the external oblique muscle and extending into the skin. There was no evidence of metastases in other parts of the body.

A biopsy was done which confirmed metastatic adenocarcinoma, most likely from the breast.

A wide local excision of the tumour was done (Figure3), which was reported as a $5 \times 2 \times 1.5 \mathrm{~cm}$ irregular mass composed of cells arranged in fused glandular formation and cribriform pattern, consistent with metastatic adenocarcinoma (Slide 4). The tumour cells are positive for ER (Slide 5), PR (Slide 6), CK7, E-cadherin and mammaglobin. The immunoprofile is consistent with a metastatic breast carcinoma. The underlying skeletal muscle was uninvolved.

Her wound had healed well. She will be started on Tamoxifen and reviewed regularly.

\section{Discussion}

Skeletal metastases from breast cancer is uncommon. There have been a few literatures reporting involvement skeletal muscles in various parts of the body. Abdominal wall muscle metastases from breast carcinoma was first reported by Ogiya et al. [2]. They reviewed 13 previously reported cases, 4 of which presented as isolated skeletal muscle metastases without other distant metastases, which is similar to this patient. However, in this patient, the metastatic lump was isolated and painless, presenting similarly to just one other patient in previous literature [3].

These metastatic lesions can be easily missed in the patients preand post-operative workups if not looked for carefully. Some literature has suggested the use of MRI and PET scans as the main modality to identify and confirm such metastatic lesions. Magnetic resonance imaging (MRI) is the gold standard for imaging muscle disease, and it shows features of muscle metastases that are relatively typical, consisting

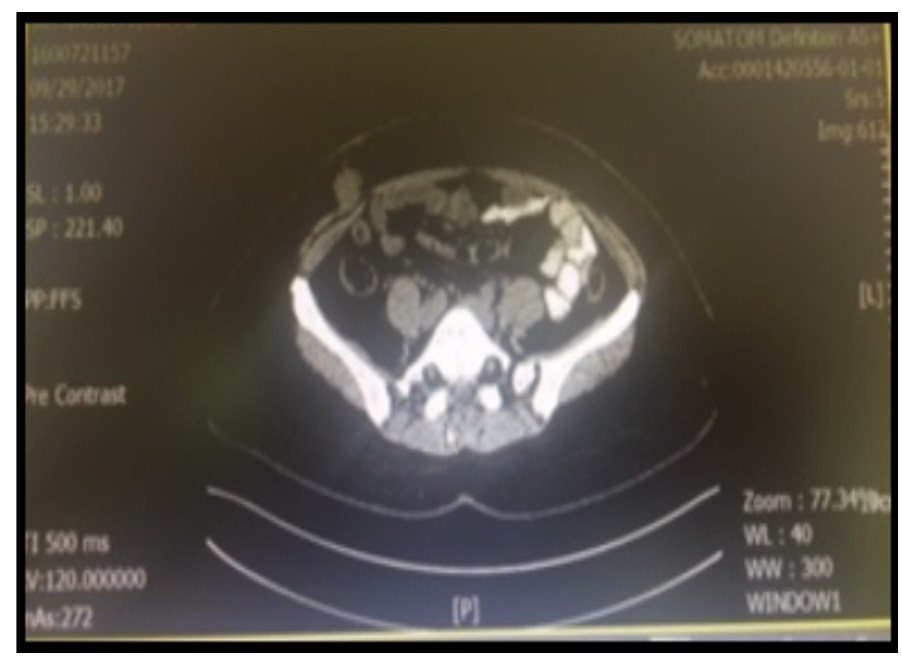

Figure 2. CT Scan Image - Restaging (August 2017).

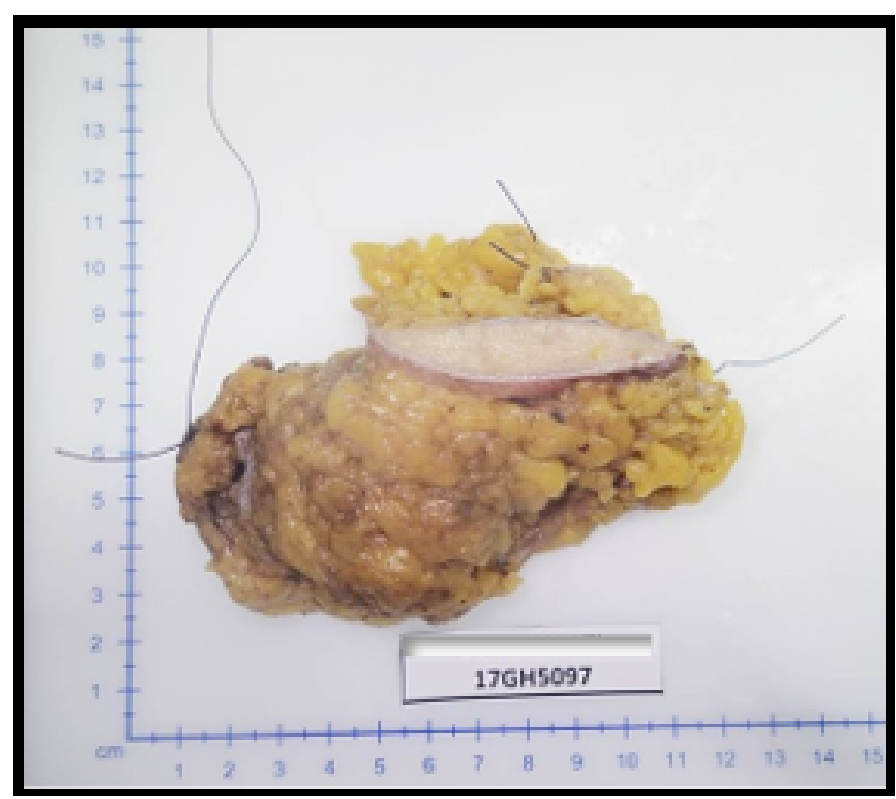

Figure 3. Gross appearance of mass removed. 


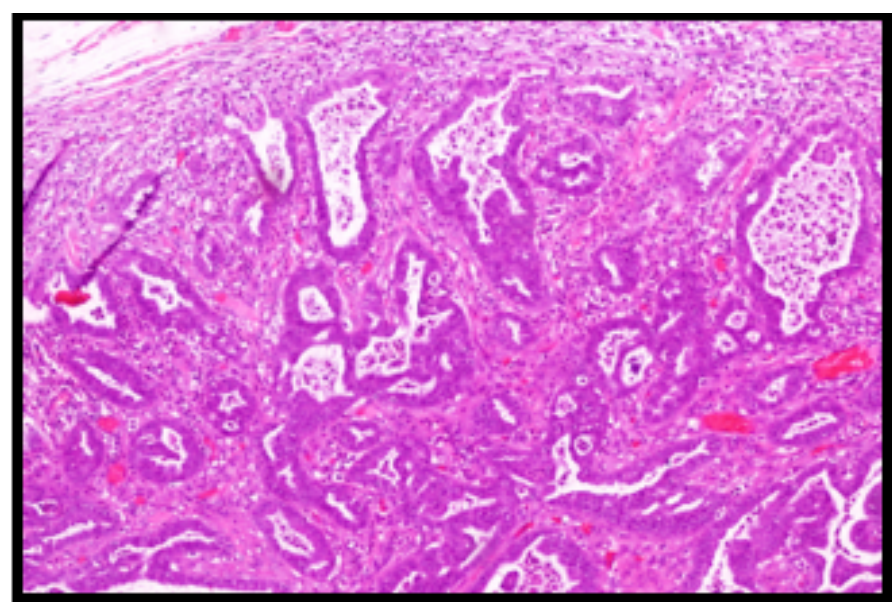

Slide 4. H\&E Section of metastatic tumour.

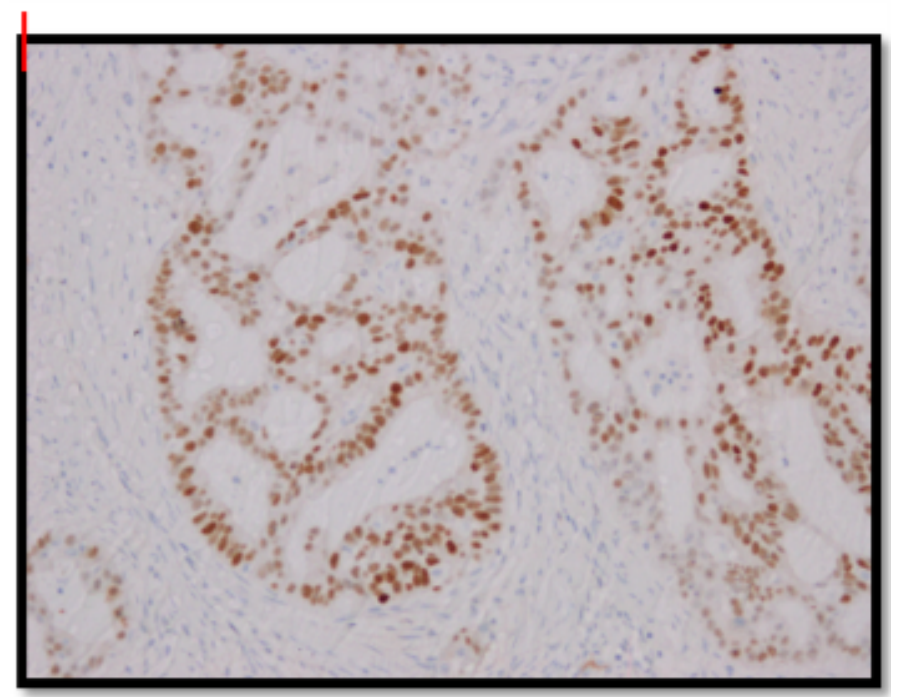

Slide 5. Section from metastatic tumour shows Estrogen Receptor positivity.

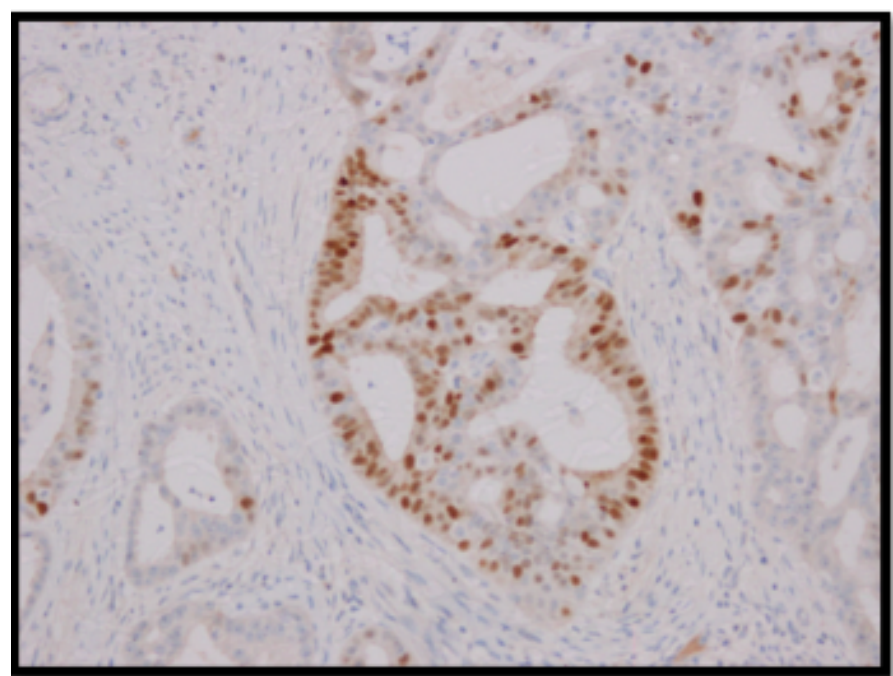

Slide 6. Section from metastatic tumour shows Progesterone Receptor positivity. of well defined intramuscular masses and marked enhancement [4]. However, in developing countries, finances and resources for such investigations are often a problem and hence not routinely used.

In this patient, the initial CT scan did make a note of a small subdermal lesion but unfortunately it was dismissed as a sebaceous cyst by the radiologist. It was asymptomatic at the time, and so both the patient and the clinician did not note it. The patient did however undergo chemotherapy after surgery to the breast. Due to financial constraints, the patient had declined Herceptin therapy for the primary breast cancer at the onset. The mass, obviously recalcitrant, did not respond well as it continued to grow till the patient presented one year later with an enlarging mass in the right side of her abdomen.

The other interesting thing noted was the change in immunochemistry of the metastatic lesion. The primary tumour was estrogen and progesterone negative, and Her-2 positive. The metastatic nodule however was noted to be estrogen and progesterone positive. Niikura et al. had reported that the incidence of discordance for ER, PR and HER2 between primary and metastatic tumours was $18.4 \%, 40.3 \%$ and $13.6 \%$ respectively [5]. As there are no clear treatment guidelines for such metastatic lesions, this change in immunohistochemistry provided us the option of putting the patient on hormonal therapy in the hope that it would control the disease. Treatment has to be individualized, based on the prognosis of the patient [6].

Due to its relatively rare occurrence, there is currently no consensus on the standard treatment for skeletal muscle metastases, and further studies are needed to determine the prognosis, and proper diagnostic and therapeutic treatment [7].

This patient will continue to be followed up closely with intermittent scans. However, her long-term prognosis is still undetermined.

\section{References}

1. Leong SPL, Cady B, Jablons DM, Garcia-Aguilar J, Reintgen D, et al. (2006) "Clinical patterns of metastasis," Cancer Metastasis Rev 25: 221-232. [Crossref]

2. Ogiya A, Takahashi K, Sato M, Kubo Y, Nishikawa N, et al. (2015) Metastatic breast carcinoma of the abdominal wall muscle: a case report. Breast Cancer 22: 206-209. [Crossref]

3. Bhattacharjee A, Md Rassell, Md Nazmul Hasan, Chandra Debnath B (2015) Abdominal wall metastasis of carcinoma breast: a case report Bangladesh Med J 44: 172-174.

4. Emmering J, Vogel WV, Stokkel MP (2012) Intramuscular metastases on FDG PET-CT: a review of the literature. Nucl Med Commun 33:117-120. [Crossref]

5. Niikura N, Liu J, Hayashi N, Mittendorf EA, Gong Y, et al. (2012) Loss of human epidermal growth factor receptor 2 (HER2) expression in metastatic sites of HER2overexpressing primary breast tumors. J Clin Oncol 30: 593-599. [Crossref]

6. NS Salemis (2015) Skeletal mucle metastasis from breast cancer: Management and literature review. Breast Dis 35: 37-40. [Crossref]

7. Kim YW, Seo KJ, Lee SL, Kwon KW, Hur J, et al. (2013) "Skeletal muscle metastases from breast cancer: two case reports," J Breast Cancer 16:117-121. [Crossref]

Copyright: (C2017 Perdamen HK. This is an open-access article distributed under the terms of the Creative Commons Attribution License, which permits unrestricted use, distribution, and reproduction in any medium, provided the original author and source are credited. 